\title{
Retinal detachment in a child with severe early childhood onset retinal dystrophy
}

\author{
Srikanta Kumar Padhy, ${ }^{1}$ Vinod Kumar, ${ }^{1}$ Brijesh Takkar, ${ }^{2}$ Sohini Mandal ${ }^{1}$
}

'Ophthalmology, Dr Rajendra Prasad center for ophthalmic sciences, New Delhi, Delhi, India ${ }^{2}$ Ophthalmology, All India Institute of Medical Science, Bhopal, Madhya Pradesh, India

\section{Correspondence to} Dr Srikanta Kumar Padhy, srikantkumar.padhy19@gmail. com

Accepted 15 August 2018

\section{DESCRIPTION}

A 10 -year-old boy was seen with the complaints of blurring of vision in his left eye (LE) since 3 months. The child had a history of poor vision in both the eyes since early childhood. There was no history of trauma. Birth and family history were insignificant. On presentation, the best corrected visual acuity in right eye (RE) was 2/60 and hand motions in LE. The spherical equivalent of refractive error was $+2.5 \mathrm{D}$ in RE and could not be determined in LE. Fat atrophy of bilateral orbits with deep-set eyeballs were noted. A left dominant alternate divergent exotropia of 90 prism dioptres was also seen. Slit lamp examination of LE revealed few pigments on corneal endothelium, posterior synechiae at 5 o'clock position, small (mention size 1 or $2 \mathrm{~mm}$ ) posterior subcapsular cataract and retrolental pigments. A relative afferent pupillary defect was present in LE. The intraocular pressure as recorded with non-contact tonometry was 14 $\mathrm{mm} \mathrm{Hg}$ and $10 \mathrm{~mm} \mathrm{Hg}$ in RE and LE, respectively. Anterior segment of the RE was normal. Dilated fundus evaluation of $\mathrm{RE}$ revealed an isolated macular coloboma measuring three disc diameters in its longest dimension (figure 1), while LE had a total retinal detachment with inferior subretinal bands and membranes, along with a macular coloboma as in the fellow eye. No retinal break could be localised, both eye (BE) optic disc was pale with slightly thin arteries. No pigmentary were apparent in either eye. Optical coherence tomography of BE macula revealed an excavation of macula with altered retinal and choroidal architecture (figure 2).

The patient was diagnosed as severe early childhood onset retinal dystrophy (SECORD) with

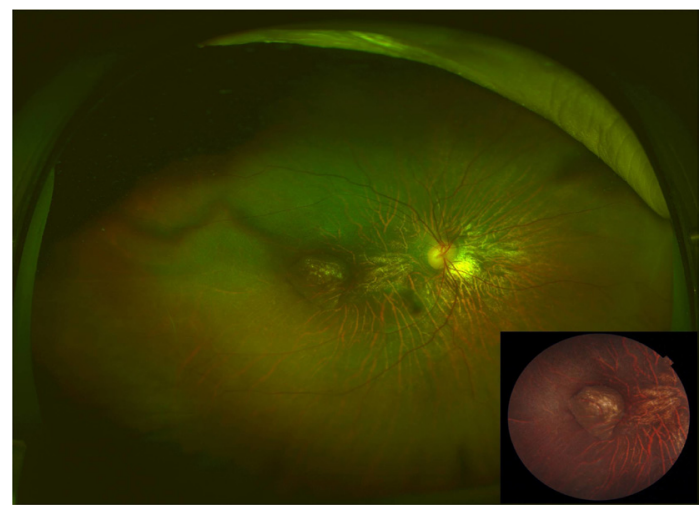

Figure 1 Ultrawide fundus image of right eye showing a pale optic disc, attenuated arteries and a macular coloboma. Inset fundus photograph shows a magnified image of the macular coloboma.

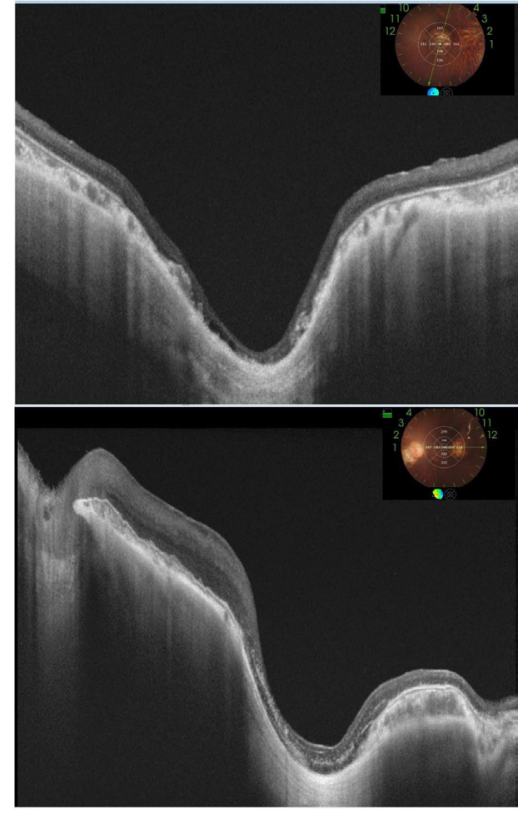

Figure 2 Swept source optical coherence tomography through macular region of right (up) and left (below, after surgery with silicone oil in situ) eyes with the inset picture showing axis of the B scan. Fovea of both eyes show poorly differentiable inner retinal layers, thinning of an excavated choroid and scleral ectasia. While right eye fovea is thin ( $98 \mathrm{u}$ ), left eye fovea is thickened ( $388 \mathrm{u}$ ). Right eye additionally shows focal areas of outer retinal cavitation, while left eye shows multiple scattered intraretinal hyper-reflective areas.

macular coloboma in BE, with a rhegmatogenous retinal detachment (RRD) in LE (in lieu of subretinal proliferative vitreoretinopathy (PVR) and pigments behind the lens\}. Detailed systemic examination of the child and ocular examination of family members revealed no abnormalities. Twenty-five-gauge vitreoretinal surgery was done under general anaesthesia for LE along with $360^{\circ}$ encircling band. No retinal break could be discerned during the surgery despite scleral depression. Two rows of laser photocoagulation was performed near the equator in $360^{\circ}$. Visual acuity in LE was $1 / 60$ at third week of follow-up, with attached retina (figure 3). Patient and family counselling was done and low vision aids suggested with a future plan of elective silicone oil removal. Gene mapping was denied by the guardians of the child due to expenditure.

This child was diagnosed to have SECORD in preference to Leber's congenital amaurosis (LCA) due to preservation of some form vision in the second decade of life and as historically the vision 


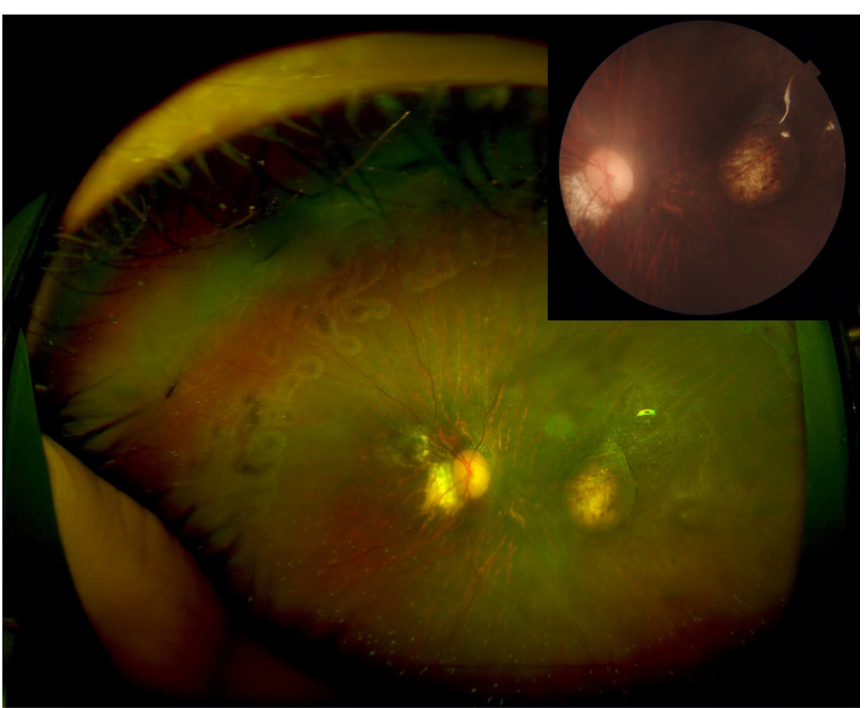

Figure 3 Ultrawide fundus image of the left eye after surgery with silicone oil in situ. Retina is attached, while site of posterior retinotomy, endolaser and indentation due to the scleral buckle can be seen. Inset fundus photograph shows a magnified view of the macular coloboma.

loss had been deciphered at around 5 years of age. ${ }^{1}$ Pseudomacular coloboma, though classically described with LCA, may be present across different phenotypes of retinitis pigmentosa (RP). It represents extensive tissue loss at fovea. ${ }^{1}$ To our knowledge, this is the first report of an RRD with LCA/SECORD. While localised RD related to coats-like reaction may occur, a case of tractional RD has been described previously in a case of CEP290-associated LCA. ${ }^{12}$ Our case and the case described by Cunningham $e t a l^{2}$ indicates the need to observe for complications and manage them appropriately despite such a setting of progressive retinal degeneration.

$\mathrm{RD}$ is a rare accompaniment of RP, perhaps due to intraretinal migration of pigment that obliterates the potential subretinal space and makes RD unlikely. For this reason, RRD rarely occurs in individuals who have the typical tapetoretinal pigmentation. ${ }^{3}$
Rishi et $a l^{3}$ have described a series of 31 patients of RP who developed RRD. Authors noted precocious vitreous degeneration with detachment of posterior vitreal cortex in a male child to have a high OR of developing RRD. Such degeneration was also noted in our case during surgery. While the least age of presentation in that series was 4 years, a diagnosis of LCA/SECORD was not specified by the authors in their series, and the authors had also included traumatic retinal dialysis and syndromic RP in their study sample. Interestingly, they found myopia to be a risk factor for RD in RP, while our patient was hypermetropic. Other considerations in such patients is a possibly higher risk of PVR.

\section{Learning points}

- Severe early childhood onset retinal dystrophy (SECORD) or Leber's congenital amaurosis (LCA) may rarely be associated with rhegmatogenous retinal detachment. This occurrence could be because of vitreous degeneration in absence of the pigmentary retinopathy that is typical of retinitis pigmentosa.

- Although SECORD or LCA can have progressive retinal degeneration, complications can occur during follow-up and may need urgent management. Hence, periodic surveillance should be done.

Contributors VK: conception of idea and drafting the work. BT, SKP and SM: drafting the work, design and acquisition of data.

Funding The authors have not declared a specific grant for this research from any funding agency in the public, commercial or not-for-profit sectors.

Competing interests None declared.

Patient consent Obtained.

Provenance and peer review Not commissioned; externally peer reviewed.

\section{REFERENCES}

1 Takkar B, Bansal P, Venkatesh P. Leber's congenital amaurosis and gene therapy. The Indian Journal of Pediatrics 2017:1-6.

2 Cunningham MA, Boldt HC, Stone EM. Retinal detachment in a patient with leber congenital amaurosis. Retin Cases Brief Rep 2013;7:102-4.

3 Rishi E, Rishi P, Bhende M, et al. Retinal detachment in 31 eyes with retinitis pigmentosa. Ophthalmol Retina 2018;2:10-16.

Copyright 2018 BMJ Publishing Group. All rights reserved. For permission to reuse any of this content visit

http://group.bmj.com/group/rights-licensing/permissions.

BMJ Case Report Fellows may re-use this article for personal use and teaching without any further permission.

Become a Fellow of BMJ Case Reports today and you can:

- Submit as many cases as you like

- Enjoy fast sympathetic peer review and rapid publication of accepted articles

- Access all the published articles

- Re-use any of the published material for personal use and teaching without further permission

For information on Institutional Fellowships contact consortiasales@bmjgroup.com

Visit casereports.bmj.com for more articles like this and to become a Fellow 